Session

\title{
Delivery of Materials Science to Engineering Freshman
}

\author{
Chris Byrne \\ Western Kentucky University, Bowling Green Kentucky
}

\begin{abstract}
This paper describes the ongoing efforts to teach introductory materials science in a course offered to first semester mechanical engineering freshman at Western Kentucky University. The WKU mechanical engineering curriculum has other introductory engineering courses which students typically take at the same time. One goal of the two courses described in this paper is to provide exposure to the type of exercises and expectations more commonly found in the later semesters. That, combined with the technical content of the course, is intended to give students a better understanding of the nature of engineering. Since the course has only been offered for the past two years, meaningful student retention data is not available. However, it is anticipated that retention of motivated, capable students will be enhanced as a result of this freshman course experience.
\end{abstract}

Students with diverse academic backgrounds are introduced to the fundamentals of engineering materials in both lecture and laboratory settings. Course objectives and relationships to program curricula are described and presented in the context of the mechanical engineering experiences expected in later courses. Issues regarding student expectations and capabilities are discussed. A manufacturing component of the course is shown to be useful in giving exposure to the application, or practice-oriented side of engineering.

The objective of this paper is to demonstrate the challenges and successes in using an engineering science course for exposing first semester students to the engineering curriculum and engineering profession. Challenges include delivery to students with limited math, chemistry and physics backgrounds. Successes include improved visibility for the students regarding the art and science of engineering and improved preparation for later mechanical engineering courses. Approaches used for continual course improvement are also reviewed.

\section{Introduction}

The typical undergraduate engineering curriculum has a single materials science course integrated into a four-year plan $^{1}$. Such courses are typically intended for sophomore or junior level students who have completed some of the introductory science courses such as physics and chemistry. Many of the Materials textbooks are designed for a student population with some calculus math skills ready to enter into a study of abstract concepts such as those underlying engineering materials. Moreover, the typical materials course is attended by students that have 
already invested considerable effort in their chosen major and have developed a certain level of maturity regarding their academic efforts.

At the same time, the successful delivery of materials topics is a challenge to many Faculty as few students possess the experience-base from which to motivate themselves in the learning process. Fundamental concepts such as dislocation movement and strengthening mechanisms can elude the most astute student when exposure to metal deformation and its related phenomena are limited or non-existent ${ }^{2}$. Some educators have implemented a more interactive style of course delivery to address student engagement ${ }^{3}$. Some programs utilize a laboratory component to the materials course in an attempt to give some hands-on experience.

As a result of time limitations, most of the topics and concepts found in the typical materials science course for mechanical engineering students are not treated in a mathematically rigorous manner. The most common math skills utilized in such courses include algebra, trigonometry (perhaps), derivatives (slopes of curves) and exponentials (kinetics related). Many of the topics covered require more conceptual reasoning than mathematical modeling. These factors make the materials course a unique experience for the typical undergraduate engineering student.

Engineers with manufacturing responsibilities typically need a significant background in materials owing to the nature of their work. Since many mechanical engineering graduates become employed in a manufacturing environment it is to their advantage to have some insight into the field. In the author's experience, many employers prefer mechanical engineering graduates to Industrial or Manufacturing engineering graduates. In light of these factors, many mechanical engineering curricula offer courses in manufacturing. Since there are always too many valuable subjects to fit within a four-year curriculum, some schools choose to offer combined manufacturing and materials courses to their students ${ }^{4}$.

New engineering programs at Western Kentucky University (WKU) have recently been implemented that are founded upon a projects-based environment with four-year integrated curricula. The programs in Civil, Electrical, and Mechanical Engineering are due to produce their first cohorts in May 2004. Owing to the "youth" of these programs, new approaches in delivering an undergraduate engineering education can be taken. This has been done with the intent of addressing many of the pitfalls often reported in both the open literature and in the academic grapevine. This paper discusses the materials science and manufacturing component of the mechanical engineering program. The objective is to highlight the differences in approaches taken to deliver the educational component while commenting on their effectiveness. How the materials component of the program is integrated into the four-year curriculum is also presented.

\section{Course Structure}

Freshmen in the Mechanical Engineering program at WKU are currently required to take 4 engineering courses. Two of the present courses are somewhat typical of introductory engineering courses at many universities. Courses ME 101 and UC 101 are designed to fulfill university general education requirements while exposing student to the engineering field. This 
course pair parallels the typical ${ }^{5}$ objectives (among others) of introductory engineering courses such as:

- the development of an appreciation for engineering

- an introduction to the discipline or to the major engineering disciplines

- the development of competency with specific engineering topics

- the building of relationships among students and between students and faculty. ${ }^{5}$

ME 101 is also designed to make the student familiar with typical machining operations and all students go through a design-build project where they actually machine parts on their own. These courses are also designed to give guidance to freshman in their study habits and provide orientation within the campus community. However, this is only a portion of the WKU mechanical engineering freshman experience. The other two required courses, ME 240 and ME 241 , are in place to give students exposure to an engineering science course with demands typical of the upper level experience.

Materials and Methods of Manufacturing (ME 240) is a course designed to give coverage of materials science for mechanical engineering students. It is also designed to give exposure to manufacturing, as appropriate for the ME student. The companion course, ME 241, is an associated laboratory course that is taken concurrently. The course prerequisites are high school physics or chemistry, and a co-requisite of college algebra. Together, ME 240 and ME 241 are unique in that the topics covered are typically seen in sophomore or junior level engineering courses. While the depth of coverage may not be as great, the placement of these courses in the freshman year allows for better integration of the mechanical systems portion of the ME curriculum and gives the student exposure to both the art and science of engineering.

The course objectives for this lecture-lab set are focused on giving coverage to most of the topical content found in traditional engineering materials courses. They are also structured to give experiences in experimental methods and in materials property testing. Exposure to manufacturing through tours of industry facilities is a major factor in the success of this course as viewed by the author and by the students who have been through the courses ( 3 cohorts to date). These field trips stimulate later discussions in the classroom and allow the student to directly see the phenomena they have studied being applied.

The learning outcomes as listed in the course syllabi are given in Table 1. These are things students should be able to the end of the course. For ME 240 these largely parallel the topics presented in the current course text (Materials and Processes in Manufacturing, $\mathrm{P}$. Degarmo, et al). For ME 241 they largely parallel the laboratory experiments the students experience. Within the allotted lab time, which is two hours once a week, tours to industry facilities are set-up where the students can see processes such as metal forming, stamping and drawing, heat treating, casting, machining centers, assembly and R\&D efforts. These industry tours consume $1 / 4$ to $1 / 3$ of the weeks in the lab course. The remaining time is spent in the lab collecting and analyzing test data. 


\begin{tabular}{|l|l|}
\hline & \multicolumn{1}{|c|}{ ME 240 Course Outcomes } \\
\hline 1 & Identify relationships between atomic bond types and material properties \\
\hline 2 & Identify relationships between micro-structures and material properties \\
\hline 3 & Characterize the solid phases present in an alloy \\
\hline 4 & Determine the influence of heat treatment on alloy properties \\
\hline 5 & Characterize the influence of temperature and time related to heat treatments \\
\hline 6 & Identify the properties unique to metals, polymers and ceramics \\
\hline 7 & Identify relationships between shaping processes and material properties \\
\hline 8 & Be familiar with common manufacturing processes \\
\hline & \\
\hline 1 & ME 241 Course outcomes \\
\hline 2 & Describe mechanism for strengthening and annealing of alloys \\
\hline 3 & Collect and analyze experimental test data \\
\hline 4 & Communicate experimental results through tables, graphs and reports \\
\hline 5 & Determine mechanical properties from experimental results \\
\hline 6 & Characterize some phase and grain structures in a material \\
\hline 7 & Have basic familiarity with several manufacturing processes \\
\hline 8 & Identify relationships between shaping processes and material properties \\
\hline
\end{tabular}

Table 1. Learning outcomes for ME 240 and ME 241.

The course expectations and grading are somewhat typical of engineering science courses. Multiple quizzes and 2 exams are used for assessing learning in the lecture course. Quizzes given weekly on reading topics are used to encourage student engagement. First giving individual quizzes and then immediately retaking the quiz in a small group encouraged student interaction with each other and the instructor. Student feedback regarding this approach was very positive. The laboratory learning assessment is performed through both short and long reports. Some exercises were performed as groups while others were as individuals. Pre-lab assignments were used to familiarize students with topics before the session. Group reports were not implemented.

\section{Integration into Curriculum}

The Materials and Methods of Manufacturing course is the first in the mechanical systems sequence of the mechanical engineering program. It is built upon at the sophomore level in a laboratory course linked with Mechanics of Deformable Bodies ("Strengths"). While learning the principle of mechanics, the sophomore lab course revisits some of the material property testing and metallurgical principles regarding material failures and strengthening mechanisms. This component of the sophomore lab is complimented by typical mechanical testing such as torsion, tension, flexure and impact methods. 
Students can gain additional exposure to engineering materials science through a technical elective in the junior or senior years. Processing and Selection of Materials, ME 450, is an upper level elective that goes deeper into the science of materials including exposure to physical metallurgy. The course also gives students experience in the selection process and further depth into process-property-performance relationships. In the future, as the programs grow, a course in Materials Failure Analysis and Characterization will be offered. This will allow a mechanical engineering student to form some specialization in their coursework.

Further student exposure to the art and science of engineering materials is likely to result in the programs at WKU. Students work with Faculty on projects both within and outside the classroom setting. The philosophy behind the programs encourages faculty-student interaction on projects. Numerous students are impacted by Faculty exposing them to their professional and scholarly activities. Faculty bring industry supported projects into courses for student participation where appropriate. Especially in the extra-curricular projects, students can take the role of learner, observer, assistant or practitioner while working with Faculty. In this environment the students can be exposed to the Faculty field of expertise and recognize them as practitioners of engineering, not simply educators. This is true for Faculty scholarship ranging from research to consulting activities. The Faculty reward system is structured to put to the forefront such interaction with students and thus provides a unique environment.

The freshman mechanical engineering courses described in this paper also give students early exposure to the Faculty of the program. Students see the Faculty first as academic advisors, then instructors, and ultimately as engineers. It has been the authors experience that the students in the freshman Materials course have been inclined to simply ask whenever an advising need arises. They know where and who their advisor is (are) and are less hesitant to seek assistance. This early familiarity with Faculty extends into the later semesters such that students tend to see the various activities and expertise of the Faculty to a degree uncommon in less integrated programs.

\section{Challenges and Successes}

One area of initial concern over the ME 240 \& ME 241 courses was the limited math background of the students. This is not an issue arising from the text used as much as with the fact that students may have limited analytical skills and may be challenged by tasks such as determining slopes or geometric quantities. Assignments and expectations did require the use of such skills and students overall performance was quite satisfactory. An additional concern regarding limited chemistry or physics backgrounds was found to be unwaranted for the courses. No time was spent on the periodic table, electron configurations or stociometry since these are areas of study in other science courses and would not add significantly to the engineering students' understanding of the material in the course. Lack of a mechanics background (physics or statics) did not appear an issue for the delivery of the topics in the courses. The student population readily understood concepts such as force and stress at the level required for introductory study of materials science and manufacturing. An end-of-semester survey allowing students to self assess their ability to meet course outcomes was conducted with the fall 2003 class. The results of this assessment are shown in figure 1. 

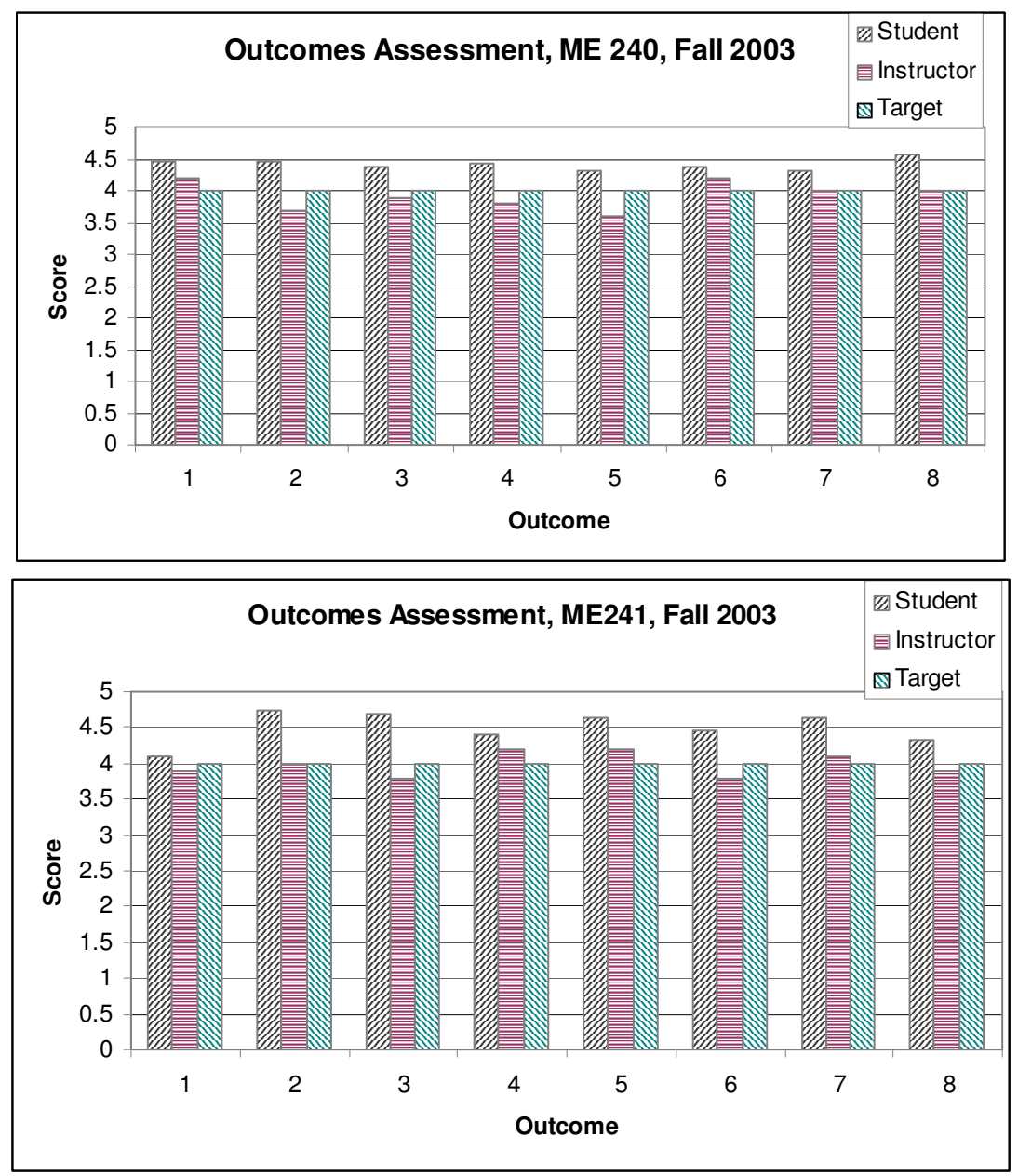

Figure 1. Assessment of outcomes for ME 240 and ME 241

Students were asked to self-rate themselves with regard to the outcomes listed in table 1. The target value of 4 was set for each outcome and the instructor evaluation was based upon student performance on quizzes and exam questions. Outcomes were judged based on $5=$ strongly agree, $4=$ agree, $3=$ neutral, $2=$ disagree, $1=$ strongly disagree. As can be seen, in all cases the students' values were higher than the target. Student self-assessment of outcomes was higher than that of the instructor, this presumably being a result of their limited knowledge of the breadth and depth of the field of study the course represents. No attempt was made to compare this course and its' outcomes to any other materials course. Overall, the assessment was viewed as quite favorable.

Along with the self-ratings of course outcomes, students responded to questions regarding adequacy of the math and chemistry backgrounds expected in the course. Student response indicated complete satisfaction with math background required for the Lab course with a score of 4.95 (scale above). The lecture course was somewhat lower, 4.35 , but still very satisfactory. The question "college chemistry or physics would be a useful prerequisite for this course" was responded to with an average score of 2.95 for the Lab and 3.65 for the lecture. Clearly students did not feel this would be needed for the Lab course which was largely a "hands-on" experience. However, there was indication that students felt the lecture course 
would benefit from such a prerequisite. This is not surprising since atomic-scale phenomena such as bond-types are covered along with crystallographic and phase phenomena. As well, some physical mechanical concepts were utilized and, depending on the student, there may be a certain degree of discomfort with some of the fundamental language of mechanics. Since no separation between chemistry and physics was contained in the question it is difficult to ascertain which area students were responding to.

The information from the prerequisite question and the assessment of outcomes suggests that there may be no need to require a different background for the courses taught. Student comments from the questionnaire give no indication that the course was difficult because of a lack of chemistry or physics background. The inference is that the course could be taught to a greater depth if such a background existed. While this may be the case, the over all response to the course was highly favorable and suggests the students call for no significant changes. With that said, there is the intent to increase the amount of math utilized in the course.

Some of the responses by the students from the self-assessment survey are interesting to note. For the lecture course these include:

- Text was valuable part of learning experience

- More Quizzes requested, they helped in learning the material

- Group quizzes were valuable learning method

- Laboratory course was invaluable in learning topics in lecture

For the Lab course these include:

- Site visits were very valuable and enjoyed by students, more requested

- Less emphasis on lab notebook

- Have more labs, especially student-run experiments

- Hard to attend many site visits (scheduling conflicts)

In general, the students were positive with regard to the connection of the lab with the lecture. The fact that some asked for more quizzes indicates they were found to be a valuable learning tool, especially in combination with the group quiz. Site visits to manufacturing industries were extremely well received, as one may expect for students in engineering. The note that it was hard to attend many trips due to scheduling was accounted for by allowing the student to choose a virtual tour using a manufacturing web-site established by Stanford University, or by attending some of the sites on their own time with prior approval from the instructor.

Instruction in a the sophomore-level "strengths" Lab course has led to greater insight into the effectiveness of the course offerings in the mechanical engineering program at WKU. In that course there is some re-visiting of the metallurgical topics covered in the freshman materials course. The author, who has been teaching both courses, finds that students come out with a greater appreciation of some of the fundamental principles of engineering materials compared to students in courses found in other programs.

\section{Conclusion}

The mechanical engineering program at WKU is utilizing freshman year "materials and methods of manufacturing" classes to in a integrated projects-based environment. The results from reviewing the first offerings of the course and its' associated lab have been presented and 
do suggest that the approach is effective at engaging students in the topics typical of an engineering materials course. Ongoing efforts to improve student learning begin with a student self-assessment and are followed-up by a Faculty peer evaluation of course effectiveness.

The Lab course structure is made possible by the close proximity of WKU to a number of industry facilities. Over 12 facilities are within a ten-minute drive from campus with many more within a 40-minute reach. Proximity, in combination with industry partner willingness to participate, allows first-hand student exposure to the manufacturing environment. These trips make for ready in-class discussions and numerous student remembrances. This is in keeping with the philosophy of the projects-based programs housed at Western Kentucky University.

\section{Bibliography}

1. Whiteman, W. \& Hitt, J. EC2000 Impact on Mechanical Engineering Curricula, Proceedings of the 2001 ASEE Annual Conference \& Exposition, Albuquerque, New Mexico.

2. Ondracek, R.P., Multimedia Virtual Laboratories for Introductory Materials Science Courses, 1999 ASEE Annual Conference \& Exposition, St Louis, Missouri.

3. Bridge, J.W., Incorporating Active Learning in an Engineering Materials Science Course, Proceedings of the 2001 ASEE Annual Conference \& Exposition, Albuquerque, New Mexico.

4. Griffin, R.B. and Creasy, T.S., The Development of a Combined Materials/Manufacturing Processes Course at Texas A\&M University, Proceedings of the 2001 ASEE Annual Conference \& Exposition, Albuquerque, New Mexico.

5. Jensen, J.N., A Case Study Approach to Freshman Engineering Courses, Proceedings of the 2003 American Society for Engineering Education Annual Conference \& Exposition, Nashville, Tennessee.

CHRIS BYRNE

Chris Byrne mainly teaches mechanical systems courses in Mechanical Engineering at WKU. This includes engineering science courses from the freshman to senior year of the program. He is active in research and industry outreach, with specialization in materials science, friction and wear mechanisms, and non-destructive evaluation. Prior to teaching at WKU, he was a faculty member of Southern Illinois University Carbondale. 